\title{
Clozapine Monitoring in Clinical Practice: Beyond the Mandatory Requirement
}

\author{
Nilamadhab Kar $^{1}$, Socorro Barreto ${ }^{1}$, Rahul Chandavarkar ${ }^{2}$ \\ ${ }^{1}$ Black Country Partnership NHS Foundation Trust, Wolverhampton, ${ }^{2}$ North Staffordshire Combined Healthcare NHS Trust, Stoke-on-Trent, \\ United Kingdom
}

\begin{abstract}
Clozapine is effective in treatment resistant schizophrenia; however, it is underutilised probably because of its side effects. The side effects are also the potential reasons for clozapine discontinuation. A mandatory requirement for its use is regular monitoring of white blood cell count and absolute neutrophil count. However there are many side effects that need monitoring in clinical practice considering their seriousness. This article tries to summarise the clinical concerns surrounding the serious side effects of clozapine some of which are associated with fatalities and presents a comprehensive way to monitor patients on clozapine in clinical practice. It emphasizes the need to broaden the monitoring beyond the mandatory investigations. This may help in improving the safety in clinical practice and increasing clinician confidence for greater and appropriate use of this effective intervention.
\end{abstract}

KEY WORDS: Clozapine; Adverse effects; Drug monitoring; Practice guideline; Safety.

\section{INTRODUCTION}

Patients with schizophrenia are known to have increased vulnerability for physical comorbidity and mortality. In addition, various neuroendocrine, cardiovascular and metabolic side effects of the antipsychotic medications increase the clinical concern further. There are however particular issues with clozapine.

Clozapine, referred to as the gold standard for the treatment of schizophrenia, ${ }^{1)}$ is the most underutilized medication; i.e., it is prescribed in only a proportion of eligible patients. The reported proportions, however, vary considerably in different regions, e.g., it is around $10-20 \%$ in United States, ${ }^{2)} 14.5-15.9 \%$ in hospitalised schizophrenia patients in 9 Asian countries; ${ }^{3)}$ whereas higher figures have been reported by studies in China $(31.9 \%),{ }^{4)}$ Australia $(33.3 \%)$ and the United Kingdom (54\%). ${ }^{5,6)}$ Its initiation is also usually delayed. ${ }^{7)}$ One of the major reasons of its inadequate use is the concern over serious side effects such as agranulocytosis, myocarditis, gastrointestinal hypo-

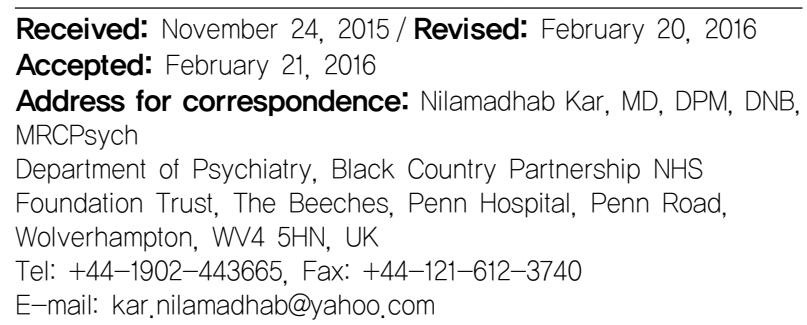

\section{Haematological Adverse Effects}

The reported incidence of clozapine-induced agranulocytosis varies between $1 \%$ to $2 \% .{ }^{11,12)}$ The observed mortality rate ranges between 0.1 and 0.3 per thousand, and the case-fatality rate is between 2.2 and 4.2 per thousand. ${ }^{8)}$ 
The incidence of leukopenia or agranulocytosis decreases over time following initiation of clozapine therapy, e.g., in the second 6 months of treatment it is reported to be 0.70 per 1,000 patient-years and after the first year, 0.39 per 1,000 patient-years. ${ }^{13)}$ The estimated case fatality rate of clozapine-induced agranulocytosis was $4.2 \%$ to $16 \%$, depending on whether a granulocyte colony-stimulating factor is used. ${ }^{13)}$

It has been reported that discontinuation of white blood cell (WBC) monitoring after 6 months of starting clozapine has similar mortality associated with other medications or even with life in general involving accidents. ${ }^{13)}$ Based on this, some authors suggest that in well informed patients wishing to stop monitoring, it may be justifiable. ${ }^{13)}$ However, late onset clozapine-induced agranulocytosis has been reported ${ }^{14-16)}$ which suggests the probable need for continued monitoring for reducing mortality.

\section{Cardiovascular Adverse Effects}

Myocarditis and cardiomyopathy are rare but serious side effects of psychotropic medications and have been specifically reported with clozapine. ${ }^{17)}$ However these are potentially reversible complications. A review of literature suggested that the risk of potentially fatal myocarditis or cardiomyopathy related to clozapine is low $(0.015 \%$ to $0.188 \%){ }^{18)}$ However, in one study, fatal outcome was associated with $46 \%$ people with clozapine induced myocarditis. ${ }^{19)}$ Most of the fatalities due to clozapine induced myocarditis have been reported during the first 6 weeks of treatment. ${ }^{19,20)}$ A study found obesity, longer duration of clozapine treatment and creatine kinase levels more than 1,000 $\mathrm{U} / \mathrm{L}$ significantly associated with fatal compared with non-fatal cases. There were no significant differences in gender, age, smoking status, dose at onset or concomitant sodium valproate use. ${ }^{20)}$

Clozapine is associated with postural hypotension; ${ }^{21)}$ and in fact, among the atypical antipsychotics this risk is considered to be highest with clozapine. ${ }^{22)}$ Although rare, orthostatic hypotension may lead to neurocardiogenic syncope. ${ }^{17)}$

Clozapine is known to have low effect on QTc. ${ }^{22)}$ Clozapine may not independently contribute to pathologic prolongation of the QTc interval, but it may occur in patients with other concurrent risk factors. ${ }^{18)}$ It is a clinical concern as QTc prolongation is associated with arrhythmic risk and may lead to dizziness, syncope, ventricular fibrillation and sudden death in specific conditions like Torsade de pointes. ${ }^{17)}$

\section{Metabolic Side Effects}

Diabetes, hypercholesterolemia, hypertriglyceridemia and obesity have been reported to be significantly associated with clozapine. ${ }^{23,24)}$ Including these specific abnormalities, metabolic syndrome with a reported range of $43.2 \%$ to $70.4 \%$ is also associated with clozapine, ${ }^{25-28)}$ which is a known cause of increased cardiovascular events and mortality. ${ }^{29-31)}$

Besides diabetes, the glycaemic dysregulation associated with clozapine range from mild glucose intolerance to diabetic ketoacidosis or hyperosmolar coma. ${ }^{8,32)}$ Diabetic ketoacidosis has been reported to be associated with fatalities. ${ }^{33,34)}$ The calculated incidence rate for diabetic ketoacidosis in clozapine treated patients was at 1.2 to 3.1 per thousand and the case-fatality rate was $20 \%$ to $31 \%$. Obesity, especially body mass index (BMI) more than 30 $\mathrm{kg} / \mathrm{m}^{2}$ have been found to increase the risk of mortality in patients receiving clozapine. ${ }^{20)}$

Considerable proportion of patients on clozapine are observed to have dyslipidaemia including hypertriglyceridemia and hypercholesterolaemia. ${ }^{27,35)}$ It is well established that dyslipidaemia increases the risk of cardiovascular and cerebrovascular morbidity and mortality.

\section{Neurological Adverse Effects}

It is known that clozapine lowers seizure threshold. Reported proportions of patients on clozapine having seizures range from $1.1 \%$ to $20 \%,{ }^{36-39)}$ and associated fatalities have been reported. ${ }^{9,40)}$ Convulsions are dose related, ${ }^{33)}$ and higher plasma clozapine concentrations have been linked to an increased risk of seizures. ${ }^{41)}$ However, it is reported that the relationship between dose and occurrence of seizures has not been statistically significant. ${ }^{42)} \mathrm{In}$ addition to seizures, clozapine-induced electroencephalogram (EEG) abnormalities like slowing and spikes have also been reported to be related to clozapine dose and plasma level. ${ }^{37)}$ Besides this, autonomic adverse effects of clozapine are common, but are usually easily managed. ${ }^{21)}$

\section{Other Serious Side Effects}

Constipation, which is a common side effect of clozapine, can have serious consequences sometimes. ${ }^{21,43)}$ The incidence for gastrointestinal hypo-motility has been reported to be 4 to 8 per thousand, which has a case-fatality rate of $15 \%$ to $27.5 \%{ }^{8)}$

\section{CLOZAPINE MONITORING}

Monitoring for the haematological side effects of cloza- 
pine is carried out mandatorily in a few countries; whereas the information from many countries is not available. It has been reported that without a monitoring service mortality rate from agranulocytosis increases. ${ }^{33)}$ While white cell monitoring is mandatory there are possible variations in different countries for example blood sugar is included in Japan. ${ }^{44)}$

In the United Kingdom, as a mandatory requirement for prescribing clozapine, white cell count with a differential count monitoring is required weekly for the initial 18 weeks, then fortnightly for up to one year, and then monthly. ${ }^{33,45)}$ Monitoring is continued throughout treatment and for at least 4 weeks after discontinuation.

British National Formulary mentions monitoring guidelines for antipsychotics in general; ${ }^{45)}$ which are understandably relevant for clozapine too. At the start of therapy with antipsychotic drugs, full blood count, urea and electrolytes and liver function test (LFT) are required and then annually thereafter. ${ }^{45)}$ Clozapine has been associated with hepatic failure and it is suggested that LFT is carried out at baseline and at 4-6 month interval. ${ }^{22)}$

It is suggested that patients with schizophrenia should have physical health monitoring (including cardiovascular disease risk assessment) at least once per year. ${ }^{45}$ ) Specifically there should be BMI and waist circumference measurements at baseline and 1 month, 3 monthly and then yearly. ${ }^{22)}$ Weight should be measured for all patients on antipsychotics at baseline, subsequently at frequent intervals during the first 3 months, at 3 months and then yearly. Patients taking clozapine require more frequent monitoring of these parameters: every 3 months for the first year, then yearly. ${ }^{45}$

Blood pressure monitoring is advised before starting therapy and frequently during dose titration of antipsychotic drugs including clozapine. $^{45)}$

An ECG may be indicated, before starting antipsychotic drugs, particularly if there are cardiovascular risk factors and personal history of cardiovascular disease. It is also suggested to have an ECG if the patient is being admitted as an inpatient. ${ }^{45)}$

Routine monitoring for myocarditis is suggested for the first 4 weeks of clozapine, and in the presence of evidence consistent with myocarditis discontinuation of clozapine is advised. Investigation by cardiac imaging will give a measure of severity and need for intervention. ${ }^{20)}$

Fasting blood glucose should be checked at baseline, after one months' treatment, then every 4-6 months in patients taking clozapine. ${ }^{45,22)}$ Lipid profile should be measured at baseline, at 3 months and then yearly for patients taking antipsychotics; however for patients on clozapine it is advised that it is done 3 monthly in the first year. ${ }^{45}$ )

It is known that prolactin is not elevated with clozapine, ${ }^{46)}$ rather a report suggested decrease in prolactin, ${ }^{47)}$ which suggests prolactin monitoring is not required for clozapine. However patients on different antipsychotics before clozapine may have their prolactin raised and it may be worthwhile to monitor prolactin in patients with symptomatic hyperprolactinaemia to evaluate any change following their switch to clozapine.

The usefulness of monitoring of plasma clozapine level in the prevention of adverse effects secondary to raised concentrations have been emphasized. ${ }^{42)}$ It may also help with optimising dosage, monitoring of adherence, drug interactions and the effect of changes in smoking habit. However, it is not a mandatory requirement. It involves measurement of plasma levels of clozapine and norclozapine (N-desmethyl-clozapine, a major metabolite of clozapine) six hours or more after the last dose of the drug (a 'trough' sample). Monitoring of clozapine level has been suggested if the dose is $600 \mathrm{mg}$ per day or more, ${ }^{48)}$ which can be done 3 monthly. ${ }^{49}$ Other indications where it may be appropriate to check clozapine level are change in smoking habit, adherence concerns, troublesome adverse effects and yearly if the treatment is successful. ${ }^{49)}$ There are variations in the reported plasma concentrations where therapeutic response was obtained, however a range of $350-400 \mu \mathrm{g} / \mathrm{L}$ is considered to be an adequate trial. ${ }^{1,50)}$ It has been proposed to maintain a safe therapeutic maximum clozapine level of $600 \mu \mathrm{g} / \mathrm{L}$ beyond which there is an increased risk of adverse effects. ${ }^{49,51)}$

Smoking has a considerable effect on clozapine dose requirement. Plasma clozapine may rise markedly within 3 to 5 days of smoking cessation and may fall rapidly if a patient on a constant dose of clozapine starts smoking. Therefore careful monitoring is essential if there is a change in smoking habit. Smoking cannabis has the same effect as smoking tobacco, whereas nicotine replacement therapy, chewing tobacco or taking 'snuff' do not affect plasma clozapine concentrations when the drug is taken at a constant dose. $^{49)}$

Besides cessation of smoking, there are other factors which can influence plasma clozapine level. Plasma levels are generally lower in males and younger patients, and higher in Asians. ${ }^{22)}$ The use of cytochrome P450 inhibitors, such as antifungals, oral contraceptives, fluvoxamine, cimetidine, erythromycin, ciprofloxacin and caffeine can increase clozapine level; ${ }^{49,52,53)}$ similarly, carbamazepine, phenytoin and possibly other enzyme inducers 
like phenobarbitone and rifampicin may decrease plasma clozapine. Fluvoxamine can increase clozapine level considerably and there are reported fatalities. ${ }^{49)}$ There are differences in reports about other selective serotonin re-uptake inhibitors; both increase, ${ }^{54,55)}$ and no effect ${ }^{49)}$ have been reported.

It has been suggested that many side effects of clozapine e.g. increases in weight and serum glucose and triglyceride levels are related to its active metabolite, norclozapine. ${ }^{56)}$ Interestingly, fluvoxamine decreases norclozapine by inhibiting the CYP450 1A2 isoenzyme. Based on this some studies suggest that careful co-administration of fluvoxamine and a low dose of clozapine, ${ }^{57)}$ may decrease norclozapine levels, while maintaining therapeutic clozapine levels; which may reduce side effects such as sedation, weight gain, metabolic disturbances and neutropenia, and may increase efficacy. ${ }^{58)}$ However, considerable concern remains with fluvoxamine-clozapine combination, as the increase in clozapine level in an individual patient may not be predictable. ${ }^{59)}$ In these circumstances, especially when drug interactions are a possibility, monitoring clozapine level becomes imperative.
An EEG is not routinely required for clozapine treatment but patients may benefit in certain conditions e.g. it may be particularly indicated for patients who have known pre-existing compromised brain function or seizures. Although EEG abnormalities are frequently reported with clozapine; ${ }^{38,60)}$ and observed to be dependent on plasma levels; ${ }^{61)}$ they do not necessarily predict the occurrence of seizures. ${ }^{60)}$ In combination with serum clozapine levels EEG may identify patients who could benefit from a reduction in clozapine dose/serum levels; ${ }^{37)}$ and this may help determine the need for valproate. ${ }^{22,62)}$ It has been claimed that change in the theta frequency in quantitative EEG may indicate clozapine treatment adequacy better than the serum level. ${ }^{63)}$ Interestingly, it has also been reported that pre-treatment EEG data may predict the clinical response to clozapine in treatment resistant schizophrenia; although this needs to be replicated in a larger sample. ${ }^{64)}$

\section{SUGGESTION FOR CLOZAPINE MONITORING IN CLINICAL PRACTICE}

Based on the available clinical evidence of various po-

Table 1. Clozapine monitoring in clinical practice

\begin{tabular}{|c|c|c|c|}
\hline Investigations & Baseline & Further testing frequency* & Yearly* \\
\hline WBC count, DC, ANC & $\times$ & Weekly for 18 weeks $^{\dagger}$, fortnightly up to one year, and then monthly & \\
\hline FBC & $\times$ & & $x$ \\
\hline Urea and electrolytes & $\times$ & & $\times$ \\
\hline LFT & $x$ & & $x$ \\
\hline Lipids & $\times$ & 3 monthly for first year & $x$ \\
\hline $\mathrm{FBG}^{\ddagger}$ & $\times$ & 1 month, every $4-6$ months & \\
\hline ECG & $\times$ & After dose changes & $\times$ \\
\hline Physical examination & $\times$ & Weekly during titration ${ }^{\dagger}$ & $x$ \\
\hline $\mathrm{BP}$, postural drop & $\times$ & Acute monitoring. Frequently during dose titration ${ }^{\dagger}$ & $x$ \\
\hline Pulse & $\times$ & Acute monitoring. Frequently during dose titration ${ }^{\dagger}$, definitely in the first $1-2$ months & $\times$ \\
\hline Temperature & $\times$ & Acute monitoring. Frequently during dose titration ${ }^{\dagger}$ & \\
\hline Weight & $\times$ & Frequently during first 3 months, every 3 months for first year & $\times$ \\
\hline BMI & $\times$ & $1,3,4-6$ monthly & $\times$ \\
\hline Waist circumference & $\times$ & $1,3,4-6$ monthly & $\times$ \\
\hline Cardiovascular monitoring & $x$ & & $x$ \\
\hline Smoking status & $\times$ & Regularly at follow-up & \\
\hline Review of co-prescribed medications & $\times$ & Regularly for drug interactions, as additional medications are prescribed & \\
\hline Serum clozapine & & As necessary. 3 monthly, if dose is $600 \mathrm{mg}$ or more & $\times$ \\
\hline Prolactin & & Not specifically needed for clozapine, consider when relevant & \\
\hline EEG & & When relevant & \\
\hline
\end{tabular}

${ }^{*}$ All the investigations/evaluations should be done more frequently if clinically indicated.

${ }^{\dagger}$ Acute monitoring: Monitor BP, pulse, temperature, after first dose, hourly for at least 3 (preferably 6) hours afterwards; This may not be required if the first dose is given at bedtime. Thereafter patient should be seen at least once a day (twice a day if faster titration is used), and BP, pulse, temperature should be monitored before and after the morning dose. Daily monitoring should be continued for at least two weeks or until there are no unacceptable adverse effects. Twice weekly monitoring may then be undertaken until a stable dose is reached. Thereafter monitor during blood testing. ${ }^{22,33)}$

${ }^{\dagger}$ Glycated haemoglobin (HbAlc) can also be checked.

WBC, white blood cell; DC, differential count; ANC, absolute neutrophil count; FBC, full blood count; LFT, liver function test; FBG, fasting blood glucose; ECG, electrocardiogram; BP, blood pressure; EEG, electroencephalogram; BMl, body mass index. 
tentially life threatening side effects and the risk of cardiovascular and metabolic disorders, further monitoring of clozapine is required beyond the mandatory haematological investigations. It is worth considering the need to update clinical guidelines for clozapine monitoring. We propose here a plan for clozapine monitoring in clinical practice based on the available evidences (Table 1).

\section{INTERVENTIONS FOLLOWING MONITORING}

Specific actions are undertaken based on the monitoring findings. Clozapine must be discontinued immediately if either the WBC count is less than $3,000 / \mathrm{mm}^{3}$ or the absolute neutrophil count (ANC) is less than $1,500 / \mathrm{mm}^{3}$ at any time during treatment; and these patients must not be re-exposed to clozapine. ${ }^{33)}$ If the WBC count is between 3,500 and $3,000 / \mathrm{mm}^{3}$ or ANC count is between 2,000 and $1,500 / \mathrm{mm}^{3}$, clozapine is continued with twice weekly blood monitoring until stabilisation or improvement. Discontinuation of clozapine is recommended if the eosinophil count rises above $3,000 / \mathrm{mm}^{3}$ or if the platelet count falls below $50,000 / \mathrm{mm}^{3}$.

Clozapine must be stopped if myocarditis or cardiomyopathy is suspected. Patient should be evaluated by cardiologist; and if myocarditis or cardiomyopathy is confirmed, patient should not be re-exposed to clozapine. ${ }^{22)}$

In addition to the investigations and specific assessments for clozapine, there is a need for usual monitoring relevant for any other medications concurrently prescribed for the patient. Monitoring for adverse effects should be considered regularly during each follow up. In addition to patient reported side-effects and clinical enquiry, use of a check-list or a side effect scale may be helpful. Clinical status such as symptomatic improvement or deterioration should be monitored preferably by a standardised scale supporting clinical assessment. This is especially important as a proportion of patients do not respond to clozapine and may require addition of other psychotropic medications. ${ }^{65,66)}$ In these scenarios clinical benefit should be balanced against the increased risk of side effects.

A structured approach to clozapine monitoring may improve the confidence of the clinicians leading to increase in the use of this effective but highly underutilised medication. In this regard, a specifically dedicated clozapine clinic may be helpful.

\section{Acknowledgments}

Authors wish to thank Quality of Life Research and
Development Foundation and Black Country Partnership NHS Foundation Trust, United Kingdom for technical and literature support. There was no funding for this article.

\section{REFERENCES}

1. Schulte P. What is an adequate trial with clozapine?: therapeutic drug monitoring and time to response in treatmentrefractory schizophrenia. Clin Pharmacokinet 2003;42:607618 .

2. Meltzer HY. Clozapine: balancing safety with superior antipsychotic efficacy. Clin Schizophr Relat Psychoses 2012; 6:134-144.

3. Xiang YT, Wang CY, Si TM, Lee EH, He YL, Ungvari GS, et al. Clozapine use in schizophrenia: findings of the Research on Asia Psychotropic Prescription (REAP) studies from 2001 to 2009. Aust N Z J Psychiatry 2011;45:968-975.

4. Si TM, Zhang YS, Shu L, Li KQ, Liu XH, Mei QY, et al. Use of clozapine for the treatment of schizophrenia: findings of the 2006 research on the china psychotropic prescription studies. Clin Psychopharmacol Neurosci 2012;10:99-104.

5. Forrester T, Siskind D, Winckel K, Wheeler A, Hollingworth S. Increasing clozapine dispensing trends in Queensland, Australia 2004-2013. Pharmacopsychiatry 2015;48: 164-169.

6. Mortimer AM, Singh P, Shepherd CJ, Puthiryackal J. Clozapine for treatment-resistant schizophrenia: National Institute of Clinical Excellence (NICE) guidance in the real world. Clin Schizophr Relat Psychoses 2010;4:49-55.

7. Nielsen J, Dahm M, Lublin H, Taylor D. Psychiatrists' attitude towards and knowledge of clozapine treatment. J Psychopharmacol 2010;24:965-971.

8. Cohen D, Bogers JP, van Dijk D, Bakker B, Schulte PF. Beyond white blood cell monitoring: screening in the initial phase of clozapine therapy. J Clin Psychiatry 2012;73:13071312.

9. Taylor DM, Douglas-Hall P, Olofinjana B, Whiskey E, Thomas A. Reasons for discontinuing clozapine: matched, case-control comparison with risperidone long-acting injection. Br J Psychiatry 2009;194:165-167.

10. Nielsen J, Correll CU, Manu P, Kane JM. Termination of clozapine treatment due to medical reasons: when is it warranted and how can it be avoided? J Clin Psychiatry 2013;74:603-613; quiz 613.

11. Alvir JM, Lieberman JA, Safferman AZ, Schwimmer JL, Schaaf JA. Clozapine-induced agranulocytosis. Incidence and risk factors in the United States. $N$ Engl J Med 1993;329:162-167.

12. Kang BJ, Cho MJ, Oh JT, Lee Y, Chae BJ, Ko J. Long-term patient monitoring for clozapine-induced agranulocytosis and neutropenia in Korea: when is it safe to discontinue CPMS? Hum Psychopharmacol 2006;21:387-391.

13. Schulte P. Risk of clozapine-associated agranulocytosis and mandatory white blood cell monitoring. Ann Pharmacother 2006;40:683-688.

14. Patel NC, Dorson PG, Bettinger TL. Sudden late onset of clozapine-induced agranulocytosis. Ann Pharmacother 2002;36:1012-1015.

15. Lahdelma L, Appelberg B. Clozapine-induced agranulocytosis in Finland, 1982-2007: long-term monitoring of patients is still warranted. J Clin Psychiatry 2012;73:837-842.

16. Singh A, Grover S, Malhotra P, Verma SC. Late onset agranulocytosis with clozapine associated with HLA DR4 responding to treatment with Granulocyte Colony-stimula- 
ting Factor: A case report and review of literature. Clin Psychopharmacol Neurosci 2016;14:212-217.

17. Mackin P. Cardiac side effects of psychiatric drugs. Hum Psychopharmacol 2008;23 Suppl 1:3-14.

18. Merrill DB, Dec GW, Goff DC. Adverse cardiac effects associated with clozapine. $J$ Clin Psychopharmacol 2005;25:32-41.

19. Hägg S, Spigset O, Bate A, Soderström TG. Myocarditis related to clozapine treatment. J Clin Psychopharmacol 2001;21:382-388

20. Ronaldson KJ, Fitzgerald PB, Taylor AJ, Topliss DJ, McNeil JJ. Clinical course and analysis of ten fatal cases of clozapine-induced myocarditis and comparison with 66 surviving cases. Schizophr Res 2011;128:161-165.

21. Chung SJ, Ahn YM, Kang UG, Koo YJ, Ha JH, Kim SW, et al. Autonomic nervous system related adverse effects developed during clozapine treatment. Korean J Psychopharmacol 2000;11:168-177.

22. Taylor D, Paton C, Kapur S. The Maudsley prescribing guidelines in psychiatry. 11th ed. Chichester, West Sussex. Wiley-Blackwell;2012.

23. Pramyothin P, Khaodhiar L. Metabolic syndrome with the atypical antipsychotics. Curr Opin Endocrinol Diabetes Obes 2010;17:460-466.

24. Stroup TS, Gerhard T, Crystal S, Huang C, Olfson M. Comparative effectiveness of clozapine and standard antipsychotic treatment in adults with schizophrenia. Am J Psychiatry 2016;173:166-173.

25. Mitchell AJ, Vancampfort D, Sweers K, van Winkel R, Yu $\mathrm{W}$, De Hert M. Prevalence of metabolic syndrome and metabolic abnormalities in schizophrenia and related disorders--a systematic review and meta-analysis. Schizophr Bull 2013;39:306-318.

26. Ahmed M, Hussain I, O'Brien SM, Dineen B, Griffin D, McDonald C. Prevalence and associations of the metabolic syndrome among patients prescribed clozapine. Ir J Med Sci 2008; 177:205-210.

27. Softic R, Sutovic A, Avdibegovic E, Osmanović E, Bećirović E, Hajdukov MM. Metabolic syndrome in schizophrenia - who is more to blame: FGA polypharmacy or clozapine monotherapy? Psychiatr Danub 2015;27:378-384.

28. Zhang Y, Chen $\mathrm{M}$, Chen J, Wu Z, Yu S, Fang Y, et al. Metabolic syndrome in patients taking clozapine: prevalence and influence of catechol-O-methyltransferase genotype. Psychopharmacology (Berl) 2014;231:2211-2218.

29. Hyde N, Dodd S, Venugopal K, Purdie C, Berk M, O'Neil A. Prevalence of cardiovascular and metabolic events in patients prescribed clozapine: a retrospective observational, clinical cohort study. Curr Drug Saf 2015;10:125-131.

30. Raedler TJ. Cardiovascular aspects of antipsychotics. Curr Opin Psychiatry 2010;23:574-581.

31. Henderson DC, Nguyen DD, Copeland PM, Hayden DL, Borba CP, Louie PM, et al. Clozapine, diabetes mellitus, hyperlipidemia, and cardiovascular risks and mortality: results of a 10-year naturalistic study. J Clin Psychiatry 2005;66:1116-1121.

32. Koller E, Schneider B, Bennett K, Dubitsky G. Clozapineassociated diabetes. Am J Med 2001;111:716-723.

33. The Electronic Medicines Compendium. Clozaril summary of product characteristics [Internet]. Leatherhead (UK): EMC; 2013 [cited 2014 Jun 28]. Available from: http://www. medicines.org.uk/emc/medicine/1277.

34. Nasrallah HA. Factors in antipsychotic drug selection: tolerability considerations. CNS Spectr 2003;8(11 Suppl 2):23-25.
35. Leonard P, Halley A, Browne S. Prevalence of obesity, lipid and glucose abnormalities in outpatients prescribed clozapine. Ir Med J 2002;95:119-120.

36. Wilson WH. Clinical review of clozapine treatment in a state hospital. Hosp Community Psychiatry 1992;43:700-703.

37. Freudenreich O, Weiner RD, McEvoy JP. Clozapine-induced electroencephalogram changes as a function of clozapine serum levels. Biol Psychiatry 1997;42:132-137.

38. Günther W, Baghai T, Naber D, Spatz R, Hippius H. EEG alterations and seizures during treatment with clozapine. A retrospective study of 283 patients. Pharmacopsychiatry 1993;26:69-74.

39. Welch J, Manschreck T, Redmond D. Clozapine-induced seizures and EEG changes. J Neuropsychiatry Clin Neurosci 1994;6:250-256.

40. Atkinson JM, Douglas-Hall P, Fischetti C, Sparshatt A, Taylor DM. Outcome following clozapine discontinuation: a retrospective analysis. J Clin Psychiatry 2007;68:1027-1030.

41. Funderburg LG, Vertrees JE, True JE, Miller AL. Seizure following addition of erythromycin to clozapine treatment. Am J Psychiatry 1994;151:1840-1841.

42. Varma S, Bishara D, Besag FM, Taylor D. Clozapinerelated EEG changes and seizures: dose and plasma-level relationships. Ther Adv Psychopharmacol 2011;1:47-66.

43. Bailey L, Varma S, Ahmad N, Gee S, Taylor DM. Factors predicting use of laxatives in outpatients stabilized on clozapine. Ther Adv Psychopharmacol 2015;5:256-262.

44. Kusumi I. [Monitoring of side effects induced by psychotropic drugs]. Seishin Shinkeigaku Zasshi 2014;116:116-122. Japanese.

45. Martin J. British National Formulary (BNF). 66th ed. London:BMJ Group;2013.

46. Meltzer HY, Goode DJ, Schyve PM, Young M, Fang VS. Effect of clozapine on human serum prolactin levels. Am J Psychiatry 1979;136:1550-1555.

47. Volavka J, Czobor P, Cooper TB, Sheitman B, Lindenmayer $\mathrm{JP}$, Citrome L, et al. Prolactin levels in schizophrenia and schizoaffective disorder patients treated with clozapine, olanzapine, risperidone, or haloperidol. J Clin Psychiatry 2004; 65:57-61.

48. Stark A, Scott J. A review of the use of clozapine levels to guide treatment and determine cause of death. Aust $N Z J$ Psychiatry 2012;46:816-825.

49. Flanagan R. Clozapine therapeutic drug monitoring: why it is important? British J Clin Pharm 2011;3:18-20.

50. Llorca PM, Lancon C, Disdier B, Farisse J, Sapin C, Auquier P. Effectiveness of clozapine in neuroleptic-resistant schizophrenia: clinical response and plasma concentrations. $J$ Psychiatry Neurosci 2002;27:30-37.

51. Simpson GM, Cooper TA. Clozapine plasma levels and convulsions. Am J Psychiatry 1978;135:99-100.

52. Cadeddu G, Deidda A, Stochino ME, Velluti N, Burrai C, Del Zompo M. Clozapine toxicity due to a multiple drug interaction: a case report. J Med Case Rep 2015;9:77.

53. Taylor D. Pharmacokinetic interactions involving clozapine. Br J Psychiatry 1997;171:109-112.

54. Spina E, Avenoso A, Facciolà G, Fabrazzo M, Monteleone $\mathrm{P}$, Maj $\mathrm{M}$, et al. Effect of fluoxetine on the plasma concentrations of clozapine and its major metabolites in patients with schizophrenia. Int Clin Psychopharmacol 1998; 13:141-145.

55. Centorrino F, Baldessarini RJ, Frankenburg FR, Kando J, Volpicelli SA, Flood JG. Serum levels of clozapine and norclozapine in patients treated with selective serotonin reuptake inhibitors. Am J Psychiatry 1996;153:820-822. 
56. Lu ML, Lane HY, Lin SK, Chen KP, Chang WH. Adjunctive fluvoxamine inhibits clozapine-related weight gain and metabolic disturbances. J Clin Psychiatry 2004;65:766-771.

57. Lu ML, Lane HY, Chen KP, Jann MW, Su MH, Chang WH Fluvoxamine reduces the clozapine dosage needed in refractory schizophrenic patients. J Clin Psychiatry 2000; 61:594-599.

58. Légaré N, Grégoire CA, De Benedictis L, Dumais A. Increasing the clozapine: norclozapine ratio with co-administration of fluvoxamine to enhance efficacy and minimize side effects of clozapine therapy. Med Hypotheses 2013;80: 689-691.

59. Olesen OV, Linnet K. Fluvoxamine-clozapine drug interaction: inhibition in vitro of five cytochrome P450 isoforms involved in clozapine metabolism. J Clin Psychopharmacol 2000; 20:35-42.

60. Treves IA, Neufeld MY. EEG abnormalities in clozapinetreated schizophrenic patients. Eur Neuropsychopharmacol 1996; 6:93-94.

61. Haring C, Neudorfer C, Schwitzer J, Hummer M, Saria A, Hinterhuber $\mathrm{H}$, et al. EEG alterations in patients treated with clozapine in relation to plasma levels. Psychopharmacology
(Berl) 1994;114:97-100.

62. Malow BA, Reese KB, Sato S, Bogard PJ, Malhotra AK, $\mathrm{Su} \mathrm{TP}$, et al. Spectrum of EEG abnormalities during clozapine treatment. Electroencephalogr Clin Neurophysiol 1994;91:205-211.

63. Gross A, Joutsiniemi SL, Rimon R, Appelberg B. Clozapineinduced QEEG changes correlate with clinical response in schizophrenic patients: a prospective, longitudinal study. Pharmacopsychiatry 2004;37:119-122.

64. Khodayari-Rostamabad A, Hasey GM, Maccrimmon DJ, Reilly JP, de Bruin H. A pilot study to determine whether machine learning methodologies using pre-treatment electroencephalography can predict the symptomatic response to clozapine therapy. Clin Neurophysiol 2010;121:1998-2006.

65. Kar N, Thirthalli J, Murali N. Efficacy of somatic treatments in treatment resistant schizophrenia [Internet]. Psychiatry On-Line; 2000 [cited at $2016 \mathrm{Feb}$ 14]. Available from: http://www.priory.com/psych/TRS.htm.

66. Singh SP, Singh V, Kar N, Chan K. Efficacy of antidepressants in treating the negative symptoms of chronic schizophrenia: meta-analysis. Br J Psychiatry 2010;197:174-179. 